ARTICLE

DOI: $10.1038 / s 41467-018-06416-6$

\title{
Simple ruthenium-catalyzed reductive amination enables the synthesis of a broad range of primary amines
}

Thirusangumurugan Senthamarai ${ }^{1}$, Kathiravan Murugesan"1, Jacob Schneidewind (1D ${ }^{1}$, Narayana V. Kalevaru', Wolfgang Baumann ${ }^{1}$, Helfried Neumann ${ }^{1}$, Paul C.J. Kamer ${ }^{1}$, Matthias Beller (i) ${ }^{1} \&$ Rajenahally V. Jagadeesh (1) ${ }^{1}$

The production of primary benzylic and aliphatic amines, which represent essential feedstocks and key intermediates for valuable chemicals, life science molecules and materials, is of central importance. Here, we report the synthesis of this class of amines starting from carbonyl compounds and ammonia by Ru-catalyzed reductive amination using $\mathrm{H}_{2}$. Key to success for this synthesis is the use of a simple $\mathrm{RuCl}_{2}\left(\mathrm{PPh}_{3}\right)_{3}$ catalyst that empowers the synthesis of $>90$ various linear and branched benzylic, heterocyclic, and aliphatic amines under industrially viable and scalable conditions. Applying this catalyst, $-\mathrm{NH}_{2}$ moiety has been introduced in functionalized and structurally diverse compounds, steroid derivatives and pharmaceuticals. Noteworthy, the synthetic utility of this Ru-catalyzed amination protocol has been demonstrated by upscaling the reactions up to 10 gram-scale syntheses. Furthermore, in situ NMR studies were performed for the identification of active catalytic species. Based on these studies a mechanism for Ru-catalyzed reductive amination is proposed.

\footnotetext{
${ }^{1}$ Leibniz-Institut für Katalyse e. V. an der Universität Rostock, Albert-Einstein-Str. 29a, 18059 Rostock, Germany. Correspondence and requests for materials should be addressed to M.B. (email: Matthias.Beller@catalysis.de) or to R.V.J. (email: Jagadeesh.Rajenahally@catalysis.de)
} 
T he development of efficient catalytic reactions for the selective and sustainable synthesis of amines from readily available and inexpensive starting materials by utilizing abundant and green reagents continues to be an important goal of chemical research ${ }^{1-6}$. In particular, the development of simple and easily accessible catalysts for reductive aminations is highly important because these reactions allow for the cost-efficient production of different kinds of amines ${ }^{7-30}$. Among reductive aminations, the reaction of carbonyl compounds with ammonia in presence of molecular hydrogen to produce primary amines is of central importance and continues to be a major challenge ${ }^{17-30}$. In general, amines are essential chemicals used widely in many research areas and industrial productions related to chemistry, medicine, biology, and material science ${ }^{1-6}$. The majority of existing pharmaceuticals, agrochemicals, biomolecules, and natural products contain amine functionalities, which constitute key structural motifs and play vital roles in their functions ${ }^{1-6}$. Among different kinds of amines, primary benzylic and aliphatic amines constitute valuable fine and bulk chemicals, that serve as versatile feedstocks and key intermediates for advanced chemicals, life science molecules and polymers ${ }^{1-34}$. Regarding their synthesis, catalytic reductive amination of carbonyl compounds (aldehydes and ketones) with ammonia in presence of molecular hydrogen represents a waste-free process to access various linear and branched benzylic and aliphatic amines ${ }^{17-27}$. In addition, catalytic amination of alcohols with ammonia also constitutes a sustainable methodology to produce primary amines ${ }^{35-38}$. Apart from transition metal-catalyzed aminations, the LeuckartWallach reaction ${ }^{39-41}$ and reduction of oxime ethers with borane ${ }^{42-44}$ have also been applied. Noteworthy, selective introduction of primary amine moieties in functionalized compounds by utilizing ammonia constitutes a benign and economic methodology ${ }^{17-27}$. Ammonia, which is produced in $>175$ million tons per year scale, is considered to be an abundant and green chemical used enormously for the large scale production of urea and other fertilizers as well as various basic chemicals ${ }^{45-50}$. Although ammonia is used extensively for the production of simple molecules, its reactions still encounter common problems such as the requirement of high temperatures or pressures and low selectivity towards the formation of a single desired product ${ }^{45-50}$. Hence, the development of more active and selective catalysts for an effective utilization of ammonia, especially for its insertion in advanced and complex molecules, is highly demanded and challenging.

Reductive amination for the preparation of primary amines, especially in industry, is mainly carried out using heterogeneous catalysts $^{17-23}$. Compared to heterogeneous catalysts, homogeneous catalysis for amination of structurally diverse molecules is less studied and remains challenging ${ }^{24-27}$. Transition metalcatalyzed reactions involving ammonia are often difficult to perform or do not even occur. This problem is mainly due to the deactivation of homogeneous catalysts by the formation of stable Werner-type ammine complexes as well as due to the harsh conditions required for the activation of ammonia. In addition, common problems in reductive aminations, such as over alkylation and reduction to the corresponding alcohols, also affect catalyst viability. In order to utilize ammonia successfully and to overcome these problems, there is a need to develop highly efficient homogeneous catalysts, which is the prime task of this investigation. To date, a few catalysts based on $\mathrm{Rh}^{-24,25}$, Ir- ${ }^{-25}$ and $\mathrm{Ru}^{26,27}$ complexes were reported for the preparation of primary amines from carbonyl compounds and ammonia using hydrogen. Initially, Beller and co-workers ${ }^{24}$ have reported a $[\mathrm{Rh}(\mathrm{COD}) \mathrm{Cl}]_{2^{-}}$TPPTS catalyst system for the synthesis of simple primary amines from aldehydes and aqueous ammonia using $\mathrm{NH}_{4} \mathrm{OAc}$ as additive. Following this work, $\mathrm{Rh}[(\mathrm{dppb})(\mathrm{COD})] \mathrm{BF}_{4}$ and $[\mathrm{Rh}(\mathrm{COD})$
$\mathrm{Cl}_{2}$-BINAS catalysts were also applied ${ }^{25}$. Next, $[\mathrm{Ir}(\mathrm{COD}) \mathrm{Cl}]_{2^{-}}$ BINAS was found to be able to catalyze the amination of a few simple ketones with ammonia ${ }^{25}$. Regarding Ru-catalysts, $\mathrm{RuHCl}$ $(\mathrm{CO})\left(\mathrm{PPh}_{3}\right)_{3}$-xantphos/-dppe in presence of $\mathrm{Al}(\mathrm{OTf})_{3}$ is known to catalyze the preparation of simple primary amines from ketones $^{26}$. Recently, $\mathrm{RuHCl}(\mathrm{CO})\left(\mathrm{PPh}_{3}\right)_{3}-(\mathrm{S}, \mathrm{S})$-f-binaphane ${ }^{27}$ in presence of $\mathrm{NaPF}_{6}$ or $\mathrm{NH}_{4} \mathrm{I}$ using $\mathrm{NH}_{3}$, as well as $\mathrm{Ru}(\mathrm{OAc})_{2}-\mathrm{C}_{3}$ TunePhos ${ }^{30}$ using $\mathrm{NH}_{4} \mathrm{OAc}$ have been used for enantioselective reductive amination of ketones to obtain chiral primary amines. These homogeneous catalysts, however, have only been applied in (enantioselective) reductive aminations of simple substrates and have not been used for the preparation of functionalized amines. Despite these advances, the design of simpler yet efficient homogeneous catalysts for the preparation of a broad range of structurally diverse primary amines is highly desired and continues to be an important task from both a research and an industry perspective.

In a lot of cases, homogeneous catalysts applied for challenging reactions and advanced organic synthesis operations are based on sophisticated or synthetically demanding metal complexes and ligands. However, a fundamental and economically important principle is that to achieve a convenient and practical chemical synthesis, the catalyst must be simple, effective and commercially available and/or easily accessible. In this regard, triphenylphosphine $\left(\mathrm{PPh}_{3}\right)$-based metal complexes are found to be expedient and advantageous for catalysis applications, since $\mathrm{PPh}_{3}$ is a stable and comparatively cheap ligand ${ }^{51-55}$. Among $\mathrm{PPh}_{3}$-based $\mathrm{Ru}$ complexes, $\mathrm{RuCl}_{2}\left(\mathrm{PPh}_{3}\right)_{3}$ is considered to be the simplest and least expensive one and is also commercially available. Interestingly, $\mathrm{RuCl}_{2}\left(\mathrm{PPh}_{3}\right)_{3}$ is known to catalyze a number of organic reactions ${ }^{56-62}$. Herein we demonstrate that $\mathrm{RuCl}_{2}\left(\mathrm{PPh}_{3}\right)_{3}$ is an efficient and highly selective homogeneous precatalyst for reductive amination, allowing the preparation of a variety of primary amines of industrial importance. By applying this $\mathrm{Ru}-$ precatalyst and starting from inexpensive and readily available carbonyl compounds (aldehydes, ketones), ammonia and molecular hydrogen, we undertook the synthesis of functionalized and structurally diverse linear and branched benzylic, heterocyclic, and aliphatic amines including drugs and steroid derivatives. Another objective is to demonstrate up-scaling of the homogeneous amination protocol to gram-scale syntheses. Furthermore, efforts were also made to identify catalytically active species and reaction intermediates by performing kinetic and in situ NMR investigations. Based on these studies, a plausible reaction mechanism is proposed.

\section{Results}

Selection of catalyst and reaction conditions. Reductive amination of benzaldehyde (1) to benzylamine (2) with ammonia using molecular hydrogen was chosen as a benchmark reaction. At first, in presence of $\mathrm{PPh}_{3}$ different metal precursors were tested. As shown in Table 1, the in situ generated Fe-, Co-, Mn-, $\mathrm{Ni}$ - and $\mathrm{Cu}-\mathrm{PPh}_{3}$ complexes were not active for the formation of benzylamine (Table 1 entries 1-5). However, in situ generated Ru (II)- $\mathrm{PPh}_{3}$ complexes showed some activity and produced benzylamine in up to $40 \%$ yield (Table 1, entries 6 and 7). After observing this reactivity, we next tested in situ generated $\mathrm{Ru}$ complexes with differently substituted $\mathrm{PPh}_{3}$-type ligands as well as simple nitrogen ligands (L1-L10). Among these, Ru-catalysts containing either $\mathrm{PPh}_{3}$ or derivatives with electron donating groups in para position showed the highest activity (Table 2; entries 1,4,5). However, none of the tested nitrogen ligands (L7-L10) produced the desired product (Table 2, entries 7-10). Unfortunately, using in situ generated Ru-complexes the yield of benzylamine did not improve beyond 53\% (Table 2). 
Table 1 Reductive amination of benzaldehyde: activity of different catalysts

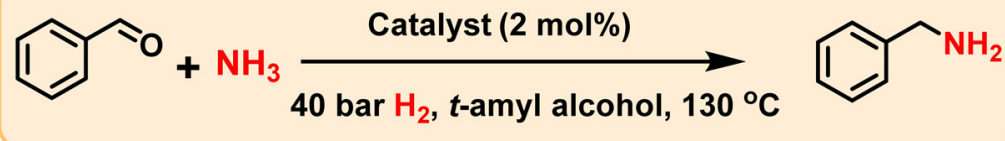

\begin{tabular}{|l|l|l|l|}
\hline Entry & Metal precursor & $\mathbf{L}$ & Yield of benzylamine [\%] \\
\hline 1 & $\mathrm{FeCl}_{2}$ & $\mathrm{PPh}_{3}$ & nd \\
\hline 2 & $\mathrm{CoCl}_{2} \cdot 6 \mathrm{H}_{2} \mathrm{O}$ & $\mathrm{PPh}_{3}$ & nd \\
\hline 3 & $\mathrm{MnCl}_{2}$ & $\mathrm{PPh}_{3}$ & nd \\
\hline 4 & $\mathrm{NiCl}_{2} \cdot 6 \mathrm{H}_{2} \mathrm{O}$ & $\mathrm{PPh}_{3}$ & nd \\
\hline 5 & $\mathrm{CuCl}_{2}$ & $\mathrm{PPh}_{3}$ & nd \\
\hline 6 & {$\left[\mathrm{RuCl}_{2}(\text { p-cymene })\right]_{2}$} & $\mathrm{PPh}_{3}$ & 40 \\
\hline 7 & {$\left[\mathrm{RuCl}_{2} \text { (benzene) }\right]_{2}$} & $\mathrm{PPh}_{3}$ & 35 \\
\hline 8 & {$\left[\mathrm{RuCl}_{2} \text { (p-cymene) }\right]_{2}$} & - & nd \\
\hline 9 & - & $\mathrm{PPh}_{3}$ & nd \\
\hline
\end{tabular}

Reaction conditions: $0.5 \mathrm{mmol}$ benzaldehyde, 2 mol\% metal precursor, $6 \mathrm{~mol}^{\circ} \mathrm{PPh}_{3}, 5-7$ bar $\mathrm{NH}_{3}, 40$ bar $\mathrm{H}_{2} 1.5 \mathrm{~mL} t$-amyl alcohol, $130{ }^{\circ} \mathrm{C}, 24 \mathrm{~h}, \mathrm{GC}$ yields using $\mathrm{n}$-hexadecane as standard $L$ Ligand, nd not detected

Next we turned our interest to molecularly defined $\mathrm{Ru}$ complexes. To our delight, the commercially available complexes $\mathrm{RuCl}_{2}\left(\mathrm{PPh}_{3}\right)_{3}$ and $\mathrm{RuCl}_{2}\left(\mathrm{PPh}_{3}\right)_{4}$ showed excellent activity and selectivity for the formation of benzylamine in 92-95\% yields (Table 2, entries 11-12). Further, Ru(tris(4methoxyphenyl)phosphine) ${ }_{3} \mathrm{Cl}_{2}$ and $\mathrm{Ru}$ (tris(4-chlorophenyl) phosphine) ${ }_{3} \mathrm{Cl}_{2}$ were also prepared and tested for their reactivity (Table 2; entries 13 and 14). The former displays similar activity compared to $\mathrm{RuCl}_{2}\left(\mathrm{PPh}_{3}\right)_{3}$ (Table 2, entry 13), while the latter was less active (Table 2, entry 14), reflecting the same ligand trend observed in case of in situ generated complexes. In presence of highly active catalysts, we observed 4-7 \% of benzyl alcohol (3) as the side-product (Table 2, entries 11-13). In case of less-active and or non-active catalysts, undesired side products such as N-benzylidenebenzylamine (4) and 2,4,5-triphenyl-2-imidazoline (5) were formed (Table 2, entries 1-10). Dibenzylamine (6) was not observed under any of these conditions.

Kinetic investigations. After having identified $\mathrm{RuCl}_{2}\left(\mathrm{PPh}_{3}\right)_{3}$ as one of the most active precatalysts, we performed kinetic investigations on this system and examined the effect of (a) reaction time, (b) catalyst concentration, (c) hydrogen pressure, (d) reaction temperature, (e) ammonia pressure, and (f) substrate (benzaldehyde) concentration on activity and product distribution (Fig. 1). For reaction time, in Fig. 1a it can be seen that after $5 \mathrm{~h}$, secondary imine 4 is predominantly present (ca. 60\%), with only $30 \%$ of target product 2 . Over the course of the reaction, 4 , which appears to be an intermediate, is consumed to yield up to $95 \% 2$ after $24 \mathrm{~h}$ (for the mechanism of this transformation vide infra). During the reaction, an increasing amount (up to 4\%) of benzyl alcohol is also formed. The cyclic side product 5 can be observed at various reaction times and its amount appears to decrease. This trend, however, is presumably an artifact of the kinetic measurements (see SI). From Fig. 1a it can be concluded that $24 \mathrm{~h}$ is an ideal reaction time to obtain maximum yield of 2 . Fig. 1b shows how catalyst loading affects the product distribution. At lower $(<2 \mathrm{~mol} \%)$ loadings, increased amounts of intermediate 4 and side product 5 are obtained, while beyond $2 \mathrm{~mol} \%$ almost no $\mathbf{4}$ or $\mathbf{5}$ along with maximum yield of $\mathbf{2}$ and some benzyl alcohol 3 were observed. A catalyst loading of $2 \mathrm{~mol} \%$ is therefore necessary to achieve excellent yield of benzylamine. Similar trends in the product distribution are observed for varied $\mathrm{H}_{2}$ pressure (Fig. 1c) and reaction temperature (Fig. 1d). Thus 40 bar $\mathrm{H}_{2}$ pressure and $130{ }^{\circ} \mathrm{C}$ reaction temperature are found to be optimum to suppress the formation of intermediates/side products (4/5) and to yield maximum amounts of the target product benzylamine. When investigating the effect of ammonia pressure, we found that at less than 5 bar side product $\mathbf{6}$ (dibenzylamine) is formed in up to $20 \%$ (Fig. 1e) yield with a concomitant decrease in the yield of 2 . Hence, a minimum $\mathrm{NH}_{3}$ pressure of $5 \mathrm{bar}$ is required to selectively form the desired product 2 (for mechanistic details vide infra). Further, on increasing the concentration of benzaldehyde ( $>0.5 \mathrm{mmol}$ ) the amount of $\mathbf{5}$ gradually increases, leading to formation of 5 in up to $80 \%$ yield (for $2 \mathrm{mmol}$ benzaldehyde) (Fig. 1e).

Synthesis of linear primary amines from aldehydes. Under optimized reaction conditions, we explored the scope of $\mathrm{RuCl}_{2}\left(\mathrm{PPh}_{3}\right)_{3}$-catalyzed reductive amination for the synthesis of 
Table 2 Reductive amination of benzaldehyde using ruthenium catalysts

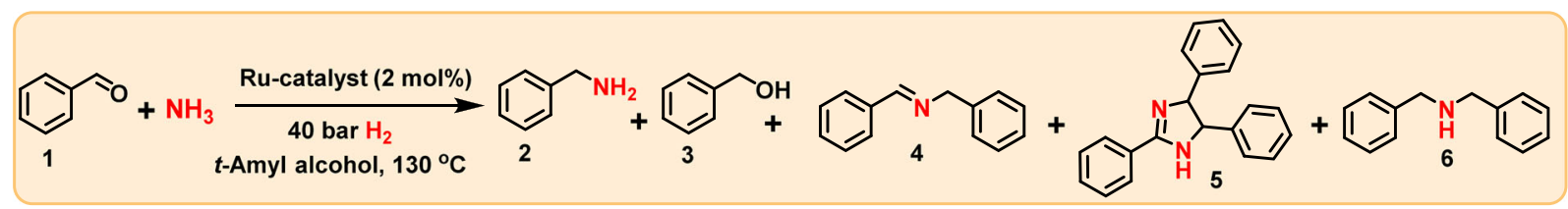

\begin{tabular}{|c|c|c|c|c|c|c|c|}
\hline \multirow[t]{2}{*}{ Entry } & \multirow[t]{2}{*}{ Ru-precursor/ Defined Ru-catalyst } & \multirow[t]{2}{*}{$\mathbf{L}$} & \multicolumn{4}{|c|}{ Yield (\%) } & \multirow[b]{2}{*}{6} \\
\hline & & & 2 & 3 & 4 & 5 & \\
\hline $1^{\mathrm{a}}$ & {$\left[\mathrm{RuCl}_{2}(\mathrm{p} \text {-cymene })\right]_{2}$} & L1 & 40 & 2 & 40 & 17 & - \\
\hline $2^{a}$ & {$\left[\mathrm{RuCl}_{2}(\mathrm{p} \text {-cymene })\right]_{2}$} & L2 & 5 & - & 60 & 33 & - \\
\hline $3^{a}$ & {$\left[\mathrm{RuCl}_{2}(\mathrm{p} \text {-cymene })\right]_{2}$} & L3 & 2 & - & 25 & 70 & - \\
\hline $4^{\mathrm{a}}$ & {$\left[\mathrm{RuCl}_{2}(\mathrm{p} \text {-cymene })\right]_{2}$} & L4 & 50 & 5 & 20 & 24 & - \\
\hline $5^{\mathrm{a}}$ & {$\left[\mathrm{RuCl}_{2}(\mathrm{p} \text {-cymene })\right]_{2}$} & L5 & 53 & 4 & 16 & 25 & - \\
\hline $6^{\mathrm{a}}$ & {$\left[\mathrm{RuCl}_{2}(\mathrm{p} \text {-cymene })\right]_{2}$} & L6 & 10 & 2 & 42 & 44 & - \\
\hline $7^{\mathrm{a}}$ & {$\left[\mathrm{RuCl}_{2}(\mathrm{p} \text {-cymene })\right]_{2}$} & L7 & - & - & 20 & 76 & - \\
\hline $8^{a}$ & {$\left[\mathrm{RuCl}_{2}(\mathrm{p} \text {-cymene })\right]_{2}$} & L8 & - & - & 18 & 79 & - \\
\hline $9^{a}$ & {$\left[\mathrm{RuCl}_{2}(\mathrm{p} \text {-cymene })\right]_{2}$} & L9 & - & - & 25 & 74 & - \\
\hline $10^{\mathrm{a}}$ & {$\left[\mathrm{RuCl}_{2}(\mathrm{p} \text {-cymene })\right]_{2}$} & L10 & - & - & 30 & 68 & - \\
\hline $11^{b}$ & $\mathrm{RuCl}_{2}\left(\mathrm{PPh}_{3}\right)_{3}$ & - & 95 & 4 & - & - & - \\
\hline $12^{b}$ & $\mathrm{RuCl}_{2}\left(\mathrm{PPh}_{3}\right)_{4}$ & - & 92 & 7 & - & - & - \\
\hline $13^{b}$ & $\mathrm{RuCl}_{2}$ (tris(4-methoxyphenyl)phosphine) ${ }_{3}$ & - & 95 & 4 & - & - & - \\
\hline $14^{\mathrm{b}}$ & $\mathrm{RuCl}_{2}$ (tris(4-chlorophenyl)phosphine) ${ }_{3}$ & - & 50 & - & 49 & - & - \\
\hline
\end{tabular}<smiles>c1ccc(P(c2ccccc2)c2ccccc2)cc1</smiles>

L1<smiles>C1CCC(P(C2CCCCC2)C2CCCCC2)CC1</smiles>

L2<smiles>Cc1cccc(P(c2ccccc2C)c2ccccc2C)c1</smiles>

L3<smiles>C/C=C\C(=C/C)P(c1ccc(C)cc1)c1ccc(I)cc1</smiles>

L4<smiles>COc1ccc(P(c2ccc(OC)cc2)c2ccc(OC)cc2)cc1</smiles>

L5<smiles>O=C(O)c1cccc(C(=O)O)n1</smiles>

L6

Reaction conditions: ${ }^{a} 0.5 \mathrm{mmol}$ benzaldehyde, $1 \mathrm{~mol} \%\left[\mathrm{RuCl}_{2} \text { (p-cymene) }\right]_{2}(2 \mathrm{~mol} \%$ with respect to the monomer), 6 mol\% ligand, 5-7 bar $\mathrm{NH}_{3}, 40$ bar $\mathrm{H}_{2} 1.5 \mathrm{~mL} t$-amyl alcohol, $130{ }^{\circ} \mathrm{C}, 24 \mathrm{~h}$, GC yields using n-hexadecane as standard. 'Same as 'a' but using $2 \mathrm{~mol} \%$ defined catalyst. 

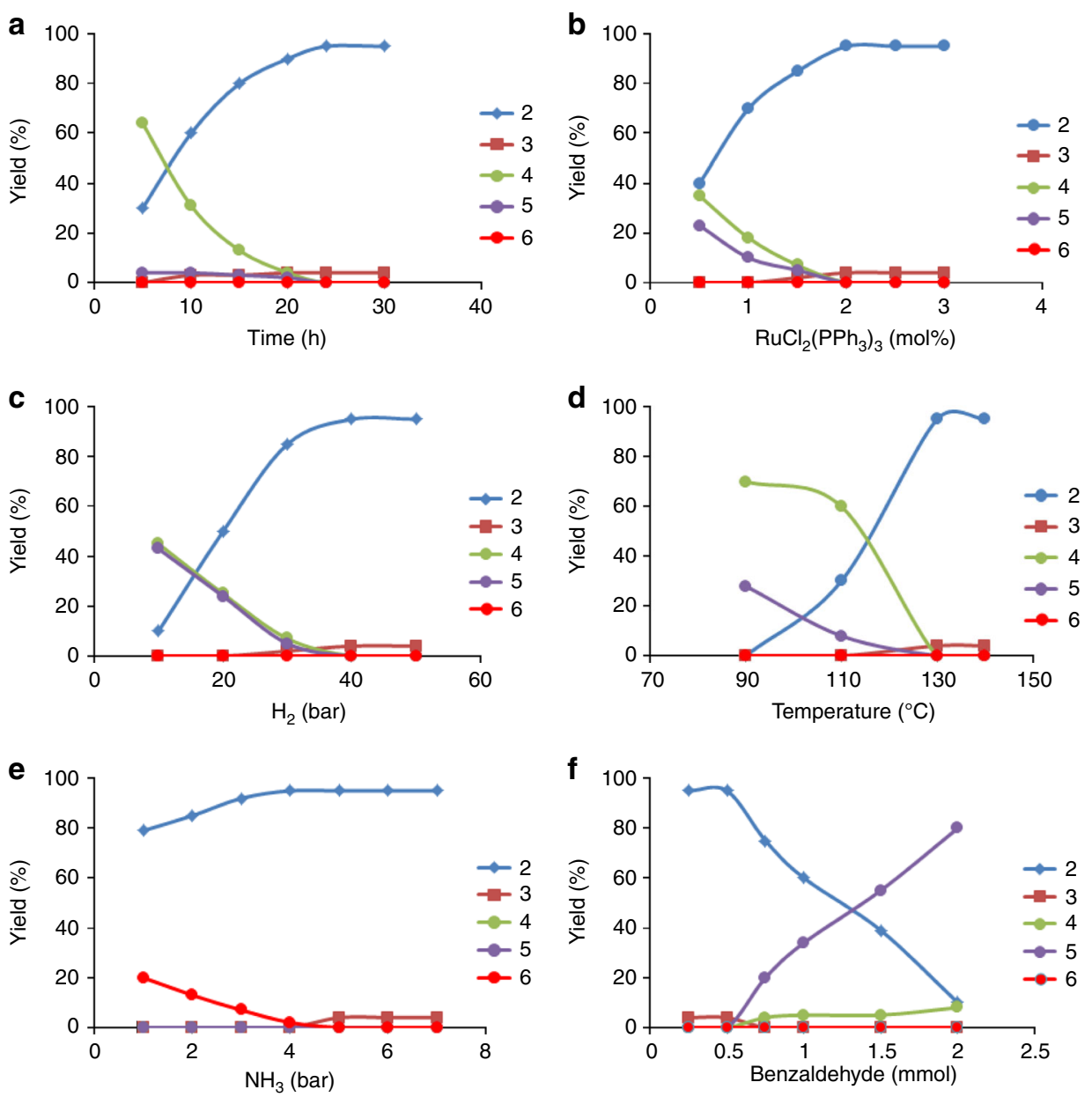

Fig. 1 Kinetic investigations on the Ru-catalyzed reductive amination of benzaldehyde. a Yield vs reaction time, $\mathbf{b}$ yield vs concentration of RuCl ${ }_{2}\left(\mathrm{PPh}_{3}\right)_{3}$, c yield vs pressure of $\mathrm{H}_{2}$, $\mathbf{d}$ yield vs temperature, e yield vs pressure of $\mathrm{NH}_{3}$, $\mathbf{f}$ yield vs concentration of benzaldehyde. $2=$ Yield of benzylamine; $3=$ yield of benzyl alcohol; 4 =yield of $\mathrm{N}$-benzylidenebenzylamine; 5 =yield of 2,4,5-triphenyl-4,5-dihydro- $1 \mathrm{H}$-imidazole, $6=$ yield of dibenzylamine. Reaction conditions: For Fig. 1a: $0.5 \mathrm{mmol}$ benzaldehyde, $2 \mathrm{~mol} \% \mathrm{RuCl}_{2}\left(\mathrm{PPh}_{3}\right)_{3}, 5-7$ bar $\mathrm{NH}_{3}, 40$ bar $\mathrm{H}_{2}, 1.5 \mathrm{~mL}$ t-amyl alcohol, $130{ }^{\circ} \mathrm{C}, 5-30$ h; for Fig. $1 \mathrm{~b}$ : $0.5 \mathrm{mmol}$ benzaldehyde, $0.5-3$ mol\% RuCl $2\left(\mathrm{PPh}_{3}\right)_{3}, 5-7$ bar $\mathrm{NH}_{3}, 40$ bar $\mathrm{H}_{2}, 1.5 \mathrm{~mL}$ t-amyl alcohol, $130{ }^{\circ} \mathrm{C}, 24 \mathrm{~h}$; for Fig. 1c: $0.5 \mathrm{mmol}$ benzaldehyde, $2 \mathrm{~mol} \%$ $\mathrm{RuCl}_{2}\left(\mathrm{PPh}_{3}\right)_{3}, 5-7$ bar $\mathrm{NH}_{3}, 10-50$ bar $\mathrm{H}_{2}, 1.5 \mathrm{~mL}$ t-amyl alcohol, $130{ }^{\circ} \mathrm{C}, 24 \mathrm{~h}$; for Fig. 1d: $0.5 \mathrm{mmol}$ benzaldehyde, $2 \mathrm{~mol}^{2} \mathrm{RuCl}_{2}\left(\mathrm{PPh}_{3}\right)_{3}, 5-7$ bar NH${ }_{3}, 40$ bar $\mathrm{H}_{2}, 1.5 \mathrm{~mL}$ t-amyl alcohol, $90-140{ }^{\circ} \mathrm{C}, 24 \mathrm{~h}$. for Fig. 1e: $0.5 \mathrm{mmol}$ benzaldehyde, $2 \mathrm{~mol} \% \mathrm{RuCl}_{2}\left(\mathrm{PPh}_{3}\right)_{3}, 1-7$ bar $\mathrm{NH}_{3}, 40$ bar $\mathrm{H}_{2}, 1.5 \mathrm{~mL} \mathrm{t}-\mathrm{amyl}$ alcohol, $130^{\circ} \mathrm{C}$, $24 \mathrm{~h}$; for Fig. 1f: 0.25-2 mmol benzaldehyde, $2 \mathrm{~mol} \% \mathrm{RuCl}_{2}\left(\mathrm{PPh}_{3}\right)_{3}, 5-7$ bar $\mathrm{NH}_{3}, 40$ bar $\mathrm{H}_{2}, 1.5 \mathrm{~mL}$ t-amyl alcohol, $130{ }^{\circ} \mathrm{C}, 24 \mathrm{~h}$. Yields were determined by GC using $n$-hexadecane as standard

various primary amines. As shown in Fig. 2, industrially relevant and structurally diverse benzylic, heterocyclic, and aliphatic aldehydes underwent reductive amination and offered linear primary amines in good to excellent yields. Simple as well as sterically hindered benzaldehydes were selectively converted to their corresponding benzyl amines in up to $95 \%$ yield (Fig. 2; products 2 and 7-13). In order to apply this amination methodology for organic synthesis and drug discovery, achieving a high degree of chemoselectivity is important. In this regard, we conducted the reaction of sensitive halogenated and functionalized benzaldehydes. Delightfully, halogen-substituted benzaldehydes, including more sensitive iodo-substituted compounds, selectively underwent reductive amination without any significant dehalogenation (Fig. 2; products 14-21). Gratifyingly, various functional groups such as ethers, thio-ethers, carboxylic acid-esters and boronic acid-esters, amides and challenging $\mathrm{C}-\mathrm{C}$ triple bonds were all well-tolerated without being reduced (Fig. 2; products 22-40). In all these cases, the aldehyde group was selectively aminated to produce functionalized amines in up to $88 \%$ yield.

Heterocycles are regarded as highly valuable compounds and these motifs serve as integral parts of a large number of life science molecules and natural products. Thus, the preparation of heterocyclic primary amines is routinely needed en route to the production of pharmaceutically and agriculturally valuable products. Consequently, a series of different heterocyclic amines were synthesized (Fig. 2; products 41-49). The primary amines of pyridine, methylenedioxybenzene and benzodioxane, furan and thiophene were obtained in $87-92 \%$ yields.

Success in the amination of aromatic and heterocyclic aldehydes prompted us to validate this catalyst also for aliphatic substrates. Commonly, amination of aliphatic aldehydes is more challenging and most reported catalysts exhibit lower reactivity towards these substrates. In addition, the reaction of aliphatic aldehydes is often troubled by the formation of unwanted aldol reaction products. In spite of these problems, the $\mathrm{RuCl}_{2}\left(\mathrm{PPh}_{3}\right)_{3}$ precatalyst is found to be highly active and selective for the preparation of aliphatic primary linear amines too (Fig. 2). Accordingly, various primary araliphatic and aliphatic linear amines including allylic ones (products $\mathbf{5 6}$ and 57) were obtained in up to $92 \%$ yield. Importantly, phenylethylamines (products $\mathbf{5 0}$ and $\mathbf{5 1}$ ), which function as monoaminergic neuromodulators and neurotransmitters in the human CNS, have been prepared in up to $90 \%$ yield. 


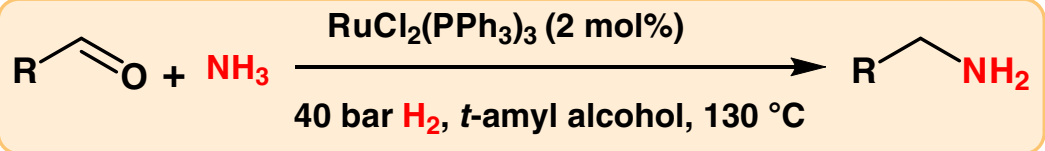<smiles>Cc1ccc(CN)cc1</smiles><smiles>CC(C)(C)c1cc(CN)cc(C(C)(C)C)c1</smiles>

13: $86 \%$<smiles>NCc1ccc(F)cc1</smiles>

$14: 92 \%$<smiles>NCc1ccc(Cl)cc1</smiles>

15: $91 \%$ b,c<smiles>NCc1ccccc1Br</smiles>

16: $85 \%^{b, c}$<smiles>NCc1ccc(Br)cc1</smiles>

17: $95 \%$ b<smiles>NCc1c(Cl)cccc1Cl</smiles>

18: $85 \%^{b, c}$<smiles>NCc1ccc(Cl)c(Cl)c1</smiles>

19: $87 \%$ c<smiles>NCc1cc(F)c(F)c(F)c1</smiles>

20: $75 \%$<smiles>NCc1ccccc1I</smiles>

21: $95 \%^{\mathrm{b}}$<smiles>COc1ccccc1CN</smiles>

22: $84 \%$<smiles>COc1ccc(CN)cc1OC</smiles>

23: $88 \%$<smiles>COc1cc(CN)cc(OC)c1</smiles>

24: $87 \%$<smiles>COc1cc(Br)c(OCOc2cc(CN)ccc2OC)cc1CN</smiles>

25: $88 \%$

26: $87 \%$

27: $88 \%$

28: $82 \%$

29: $72 \%$ b,c

30: $89 \%$<smiles>COc1cc(CN)ccc1OCc1ccccc1COc1ccc(CN)cc1COc1ccc(CN)cc1COc1ccc(CN)c(Cl)c1</smiles>
31: $81 \%$

33: $79 \%$

34: $80 \%$<smiles>CSc1ccc(CN)cc1</smiles><smiles>NCc1ccc2c(c1)OCO2</smiles><smiles>NCc1ccc2c(c1)OCCO2</smiles><smiles>NCc1ccco1</smiles>
45: $85 \%$

41: $92 \%$,c

42: $80 \%^{\mathrm{b}}$

43: $88 \%$

44: $87 \%$<smiles>CC(CN)c1ccccc1</smiles><smiles>NCCc1ccccc1</smiles>

50: $89 \%{ }^{\mathrm{b}}$

49: $92 \%$

(Phenylethylamine)

51: $90 \%$ b

(B-Methylphenethylamine)<smiles></smiles>

46: $71 \%$<smiles></smiles>

53: $88 \%^{c}$<smiles>NCC(c1ccccc1)c1ccccc1</smiles>
54: $87 \%^{c}$<smiles>CC(CN)Cc1ccc(C(C)(C)C)cc1</smiles><smiles>C=C(C)C1CC=C(CN)CC1</smiles><smiles>CC1(C)C2C=CC1C2CN</smiles>

57: $89 \%$<smiles>NCCCc1ccccc1</smiles>

52: $84 \%^{b}$<smiles>CCCCCCCCNCCCC(C)CC(C)(C)CCCN</smiles>

59: $89 \%$ b,c

60: $83 \%^{\mathrm{b}}$

$61: 80 \%$

Fig. 2 Ru-catalyzed synthesis of linear primary benzylic, heterocyclic, and aliphatic amines. aReaction conditions: a $0.5 \mathrm{mmol}$ aldehyde, 2 mol\%

$\mathrm{RuCl}_{2}\left(\mathrm{PPh}_{3}\right)_{3}, 5-7$ bar $\mathrm{NH}_{3}, 40$ bar $\mathrm{H}_{2} 1.5 \mathrm{~mL}$-amyl alcohol, $130^{\circ} \mathrm{C}, 24 \mathrm{~h}$, isolated yields. 'b $\mathrm{GC}$ yields using n-hexadecane as standard. 'same as 'a' for $30 \mathrm{~h}$. Isolated as free amines and converted to hydrochloride salts. Corresponding hydrochloride salts were subjected to NMR analysis 


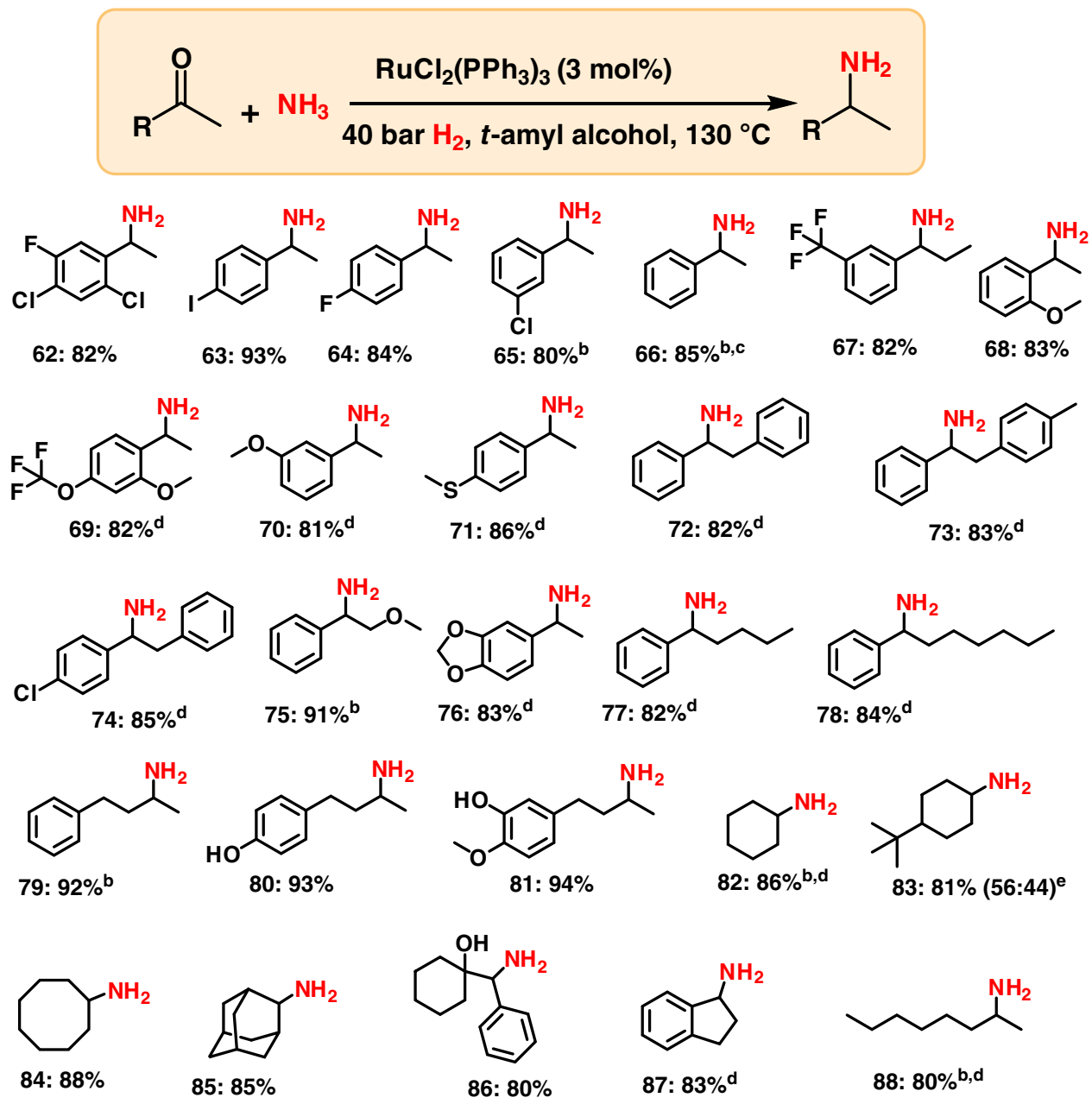

Fig. $3 \mathrm{RuCl}_{2}\left(\mathrm{PPh}_{3}\right)_{3}$-catalyzed synthesis of branched primary amines from ketones. aReaction conditions: $0.5 \mathrm{mmol}$ ketone, $3 \mathrm{~mol} \% \mathrm{RuCl}_{2}\left(\mathrm{PPh}_{3}\right)_{3}, 5-7$ bar $\mathrm{NH}_{3}, 40$ bar $\mathrm{H}_{2} 1.5 \mathrm{~mL} t$-amyl alcohol, $130^{\circ} \mathrm{C}, 24 \mathrm{~h}$, isolated yields. ${ }^{b} \mathrm{GC}$ yields using n-hexadecane as standard. 'Same as 'a' with 1 mol\% catalyst. 'Same as ' $a$ ' for $30 \mathrm{~h}$. eDiastereomeric ratio. Isolated as free amines and converted to hydrochloride salts. Corresponding hydrochloride salts were subjected to NMR analysis

Synthesis of branched primary amines from ketones. After having successfully performed the reductive amination of aldehydes, we were interested in the general applicability of this ruthenium precatalyst for the synthesis of branched primary amines starting from different ketones (Fig. 3). Compared to aldehydes, the reaction of ketones with ammonia to form primary amines is more difficult. Remarkably, the $\mathrm{RuCl}_{2}\left(\mathrm{PPh}_{3}\right)_{3}$ precatalyst is also active towards aromatic ketones (Fig. 3). Further, the applicability of this catalyst system was also explored for aliphatic ketones. Here, the aliphatic branched primary amines were obtained in up to $94 \%$ yield (Fig. 3 ).

Applications to life science molecules. To showcase the valuable applications of this amination protocol, we carried out the preparation of existing drugs as well as the introduction of $-\mathrm{NH}_{2}$ moieties into drugs and complex molecules. The amination of important drugs such as Nabumetone, Pentoxifylline, and Azaperone (Fig. 4; products 92-94) as well as steroid derivatives has been demonstrated (Fig. 4; products 95-97). Such an insertion of amino groups into life science molecules represents a resourceful technique for further functionalization and modulation of their activities, which is highly useful in drug discovery.

Upscaling for the preparation of amines on gram-scale. In order to show practical utility and to demonstrate potential for implementation in industrial production, the upscaling of synthetic methodologies is very important. Especially in homogeneous catalysis upscaling is a challenging task. Therefore, to demonstrate the applicability of this homogeneous catalytic amination protocol, we performed gram-scale synthesis of six selected amines. As shown in (see Supplementary Figure 1), 2-10 g of four aldehydes and two ketones were successfully aminated to yield their corresponding primary amines in more or less similar yields to those of $50-100 \mathrm{mg}$ scale reactions.

We were interested to compare our methodology to an established amination protocol. The Leuckart-Wallach reaction is a prime example, finding application also on an industrial scale $^{39-41}$. We therefore subjected 15 aldehydes and ketones, which have been studied in this work, to Leuckart-Wallach reaction conditions ${ }^{39-41}$ to prepare the corresponding primary amines. As shown in Supplementary Table 1, the reaction worked well for simple aldehydes/ketones and gave $53-75 \%$ of corresponding primary amines (Supplementary Table 1; entries 1-3). For a majority of substituted and structurally diverse as well as heterocyclic aldehydes and ketones it gave poor yields (5-15\%) (Supplementary Table 1; entries 4-9). The Leuckart-Wallach reaction failed to yield the desired primary amine for sensitive substrates (e.g., TMS or halogen containing) as well as some (hetero)cyclic and steroid derivatives (Supplementary Table 1; entries 10-15). A majority of the sensitive functional groups were 
<smiles>COc1ccccc1CC(C)N</smiles>

89: $85 \%$ (2-Methoxyamphetamine)<smiles>COc1ccc2cc(CCC(C)N)ccc2c1</smiles>

(Nabumetone- $\mathrm{NH}_{2}$ )

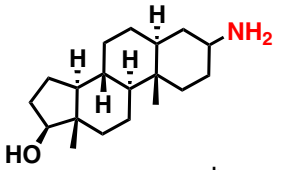

95: $93 \%(92: 8)^{b}$

(Androstanolone- $\mathrm{NH}_{2}$ )

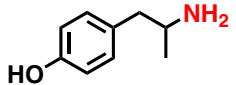

90: $92 \%$

(4-Hydroxyamphetamine)<smiles>CC(N)CCCCn1c(=O)[nH]c2ncn(C)c2c1=O</smiles>

(Pentoxifylline- $\mathrm{NH}_{2}$ )

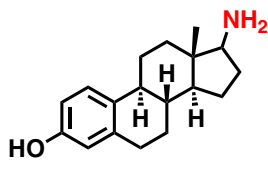

96: $79 \%(52: 48)^{b}$

(Estrone- $\mathrm{NH}_{2}$ )<smiles>COc1cc(CC(C)N)ccc1O</smiles>

91: $82 \%$

(4-Hydroxy-3-methoxyamphetamine)

Fig. 4 Synthesis of drugs and amination of complex molecules. aReaction conditions: 0.5 mmol ketone, $3 \mathrm{~mol}_{2} \mathrm{RuCl}_{2}\left(\mathrm{PPh}_{3}\right)_{3}, 5-7$ bar $\mathrm{NH}_{3}, 40$ bar $\mathrm{H}_{2}$ $1.5 \mathrm{~mL} \mathrm{t}$-amyl alcohol, $130^{\circ} \mathrm{C}, 24 \mathrm{~h}$, isolated yields. Isolated as free amines and converted to hydrochloride salts. Corresponding hydrochloride salts were subjected to NMR analysis. ${ }^{b}$ Diastereomeric ratio

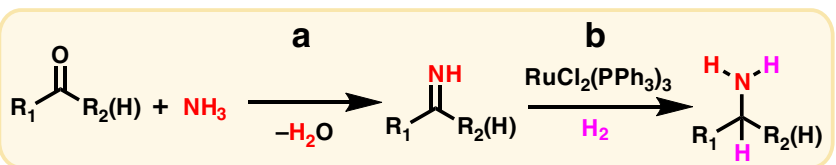

Fig. 5 Ru-catalyzed reductive amination of carbonyl compounds with $\mathrm{NH}_{3}$ using $\mathrm{H}_{2}$. a Noncatalytic condensation reaction; b catalytic hydrogenation reaction

not tolerated. Gratifyingly, for all these substrates, the $\mathrm{RuCl}_{2}\left(\mathrm{PPh}_{3}\right)_{3}$ precatalyst using ammonia and hydrogen worked well and produced the corresponding primary amines in $72-93 \%$ yields. These results clearly reveal that catalytic reductive amination using $\mathrm{RuCl}_{2}\left(\mathrm{PPh}_{3}\right)_{3}$ is more generally applicable for the preparation of primary amines compared to the traditional Leuckart-Wallach reaction.

\section{Discussion}

A general reaction pathway for the catalytic reductive amination of carbonyl compounds is shown in Fig. 5. Initially, the carbonyl compound undergoes condensation with ammonia to form the corresponding primary imine. Subsequently, the intermediate imine is hydrogenated to give the primary amine. The hydrogenation step is catalyzed by a catalytic species derived from the precatalyst, $\mathrm{RuCl}_{2}\left(\mathrm{PPh}_{3}\right)_{3}$.

We were interested to gain mechanistic insight into the hydrogenation step and to determine the nature of the active catalyst species. For this purpose, we studied the interaction of $\mathrm{RuCl}_{2}\left(\mathrm{PPh}_{3}\right)_{3}$ with hydrogen using in situ NMR in a model system consisting solely of the ruthenium precatalyst, methanol and $\mathrm{C}_{6} \mathrm{D}_{6}$. Figure 6 depicts the hydride region of the obtained ${ }^{1} \mathrm{H}$ NMR spectra. Initially, even in the absence of $\mathrm{H}_{2}$, a quartet at $\delta_{\mathrm{H}}=-17.6 \mathrm{ppm}$ is observed along with a broad singlet at $\delta_{\mathrm{P}}=55 \mathrm{ppm}$ in the ${ }^{31} \mathrm{P}\left\{{ }^{1} \mathrm{H}\right\} \mathrm{NMR}$ spectrum (see SI). We assign these signals to $\left[\mathrm{RuHCl}\left(\mathrm{PPh}_{3}\right)_{3}\right]^{63}$, which is likely formed in small amounts via methanol oxidation. In presence of $\mathrm{H}_{2}(1.5 \mathrm{bar})$ at room temperature, the quartet corresponding to $\left[\mathrm{RuHCl}\left(\mathrm{PPh}_{3}\right)_{3}\right]$ broadens ${ }^{63}$ and two new hydride signals appear: a broad singlet at $\delta_{\mathrm{H}}=-12.5 \mathrm{ppm}$ and a triplet of triplets at $\delta_{\mathrm{H}}=-10.9 \mathrm{ppm}$. Using ${ }^{1} \mathrm{H}_{-}{ }^{31} \mathrm{P}$ HMBC NMR (see Supplementary Figures 6-13) we were able to assign the hydride triplet of triplets to two multiplets in the ${ }^{31} \mathrm{P}\left\{{ }^{1} \mathrm{H}\right\}$ NMR spectrum $\left(\right.$ at $\delta_{\mathrm{P}}=34.8 \mathrm{ppm}$ and $\delta_{\mathrm{P}}=58.4$ ppm; see SI), which is consistent with the structure of $[\mathrm{Ru}$ $\left.(\mathrm{H})_{2}\left(\mathrm{PPh}_{3}\right)_{4}\right]^{64}$. We tentatively assign the broad singlet at $\delta_{\mathrm{H}}=$ $-12.5 \mathrm{ppm}$ to $\left[\mathrm{Ru}(\mathrm{H})_{2}\left(\mathrm{PPh}_{3}\right)_{3}\right]$, which is corroborated by the appearance of a broad signal at $\delta_{\mathrm{P}}=58 \mathrm{ppm}$ in the ${ }^{31} \mathrm{P}\left\{{ }^{1} \mathrm{H}\right\} \mathrm{NMR}$ spectrum $^{65}$. $\left[\mathrm{Ru}(\mathrm{H})_{2}\left(\mathrm{PPh}_{3}\right)_{3}\right]$ would be in equilibrium with $[\mathrm{Ru}$ $\left.(\mathrm{H})_{2}\left(\mathrm{PPh}_{3}\right)_{4}\right]$ via association/dissociation of a $\mathrm{PPh}_{3}$ ligand. After $2.5 \mathrm{~h}$ at room temperature a new triplet at $\delta_{\mathrm{H}}=-9.4 \mathrm{ppm}$ appears in the hydride region, which further increases in intensity upon heating to $60{ }^{\circ} \mathrm{C}$. Using ${ }^{1} \mathrm{H}^{3}{ }^{31} \mathrm{P}$ HMBC NMR we could assign this hydride signal to a singlet in the ${ }^{31} \mathrm{P}\left\{{ }^{1} \mathrm{H}\right\}$ NMR spectrum at $\delta_{\mathrm{P}}=50.4 \mathrm{ppm}$ (see Supplementary Figures 6-13). After $1.5 \mathrm{~h}$ at $60^{\circ} \mathrm{C}$, it is the dominant species in the hydride region and in the ${ }^{31} \mathrm{P}\left\{{ }^{1} \mathrm{H}\right\}$ NMR spectrum. The triplet hydride splitting $(37 \mathrm{~Hz})$, which collapses to a singlet in the ${ }^{1} \mathrm{H}\left\{{ }^{31} \mathrm{P}\right\}$ NMR spectrum (see Supplementary Figures 6-13), indicates the presence of just two equivalent $\mathrm{PPh}_{3}$ ligands. When the ${ }^{31} \mathrm{P}\left\{{ }^{1} \mathrm{H}\right\}$ NMR experiment is decoupled with reduced power (only aromatic protons are decoupled) the singlet at $\delta_{\mathrm{P}}=50.4 \mathrm{ppm}$ splits into a doublet (see Supplementary Figures 6-13)), indicating a monohydride structure. Although this species appears to have only two $\mathrm{PPh}_{3}$ and one hydride ligand, its accumulation indicates high stability under experimental conditions, suggesting the presence of other stabilizing ligands (such as CO). Since [Ru $(\mathrm{H})_{2}\left(\mathrm{PPh}_{3}\right)_{3}$ ] is known to decarbonylate methanol ${ }^{66}$ and due to similar spectral characteristics compared to $[\mathrm{RuHCl}(\mathrm{CO})$ $\left(\mathrm{PPh}_{3}\right)_{2}$ (pyrazine) $]^{67}$ we tentatively assign this species to the carbonyl-containing complex $\left[\mathrm{RuHCl}(\mathrm{CO})\left(\mathrm{PPh}_{3}\right)_{2}(\mathrm{Y})\right]$ (with $\mathrm{Y}$ possibly being a solvent molecule) formed via methanol decarbonylation.

An overview of the proposed transformation of $\mathrm{RuCl}_{2}\left(\mathrm{PPh}_{3}\right)_{3}$ in our model system is provided in Fig. 7: $\mathrm{RuCl}_{2}\left(\mathrm{PPh}_{3}\right)_{3}$ undergoes a stepwise reaction with $\mathrm{H}_{2}$ to form $\left[\mathrm{RuHCl}\left(\mathrm{PPh}_{3}\right)_{3}\right]$ (which is also generated by the reaction with methanol) and $\mathrm{Ru}$ $(\mathrm{H})_{2}\left(\mathrm{PPh}_{3}\right)_{3}$, which is in equilibrium with $\mathrm{Ru}(\mathrm{H})_{2}\left(\mathrm{PPh}_{3}\right)_{4}$. $\mathrm{Ru}$ $(\mathrm{H})_{2}\left(\mathrm{PPh}_{3}\right)_{3}$ can further react via alcohol decarbonylation to form the carbonyl-containing complex $\left[\mathrm{RuHCl}(\mathrm{CO})\left(\mathrm{PPh}_{3}\right)_{2}(\mathrm{Y})\right]$. While methanol is not present under our reaction conditions for reductive amination, it is known that $\mathrm{RuCl}_{2}\left(\mathrm{PPh}_{3}\right)_{3}$ can also enable the decarbonylation of benzyl alcohols and aldehydes ${ }^{65}$, which constitute a majority of our substrates. 

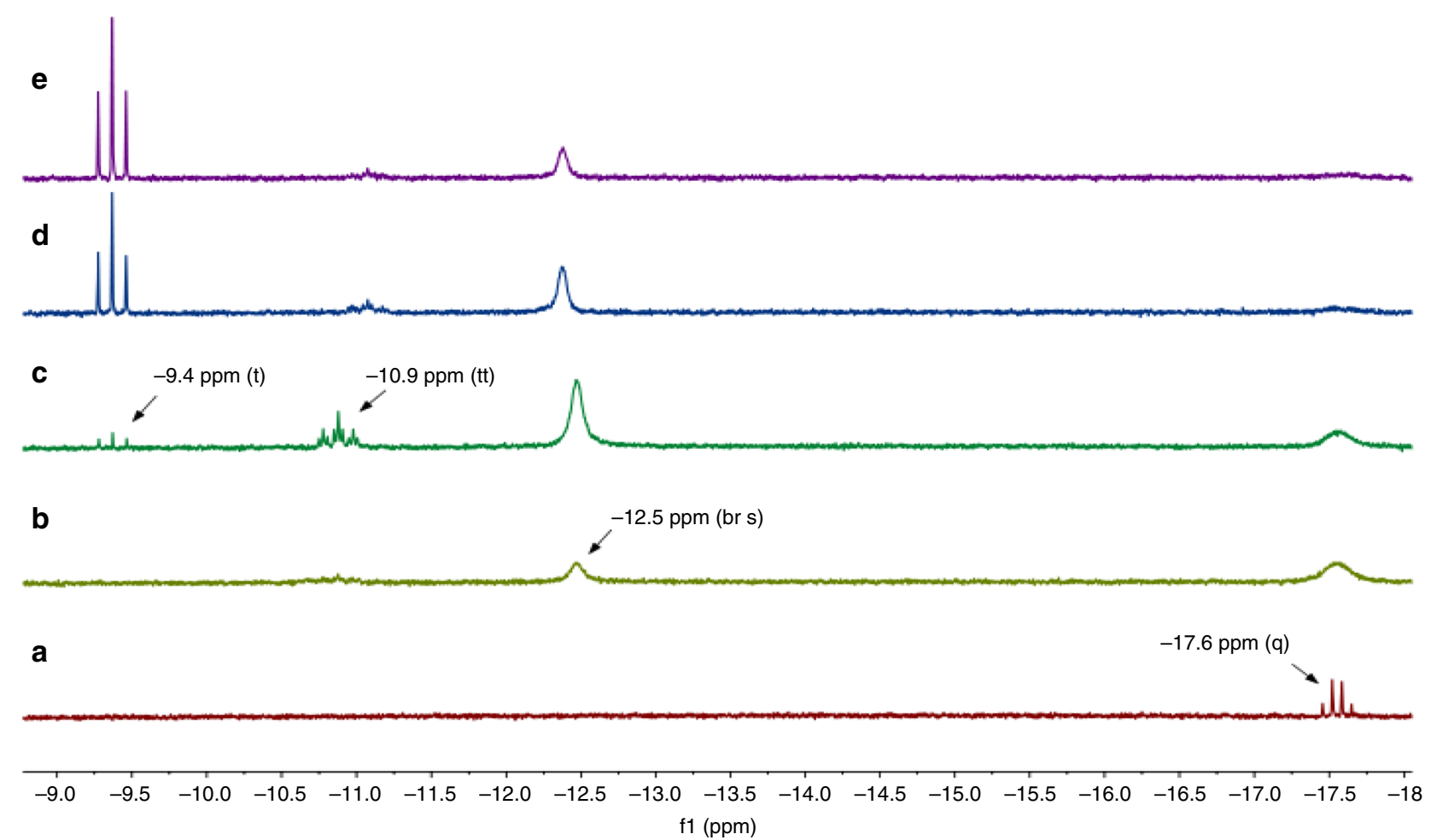

Fig. 6 Hydride region of ${ }^{1} \mathrm{H}$ NMR spectra of $\mathrm{RuCl}_{2}\left(\mathrm{PPh}_{3}\right)_{3}$ in $\mathrm{C}_{6} \mathrm{D}_{6}$ /methanol. a RT, argon atmosphere; b RT, $\mathrm{H}_{2}$ atmosphere (1.5 bar), 10 min; $\mathbf{c}$ RT, $\mathrm{H}_{2}$ atmosphere (1.5 bar), $2.5 \mathrm{~h}$; d $60^{\circ} \mathrm{C}, \mathrm{H}_{2}$ atmosphere (1.5 bar), $30 \mathrm{~min}$; e $60^{\circ} \mathrm{C}, \mathrm{H}_{2}$ atmosphere $(1.5 \mathrm{bar}), 1.5 \mathrm{~h}$

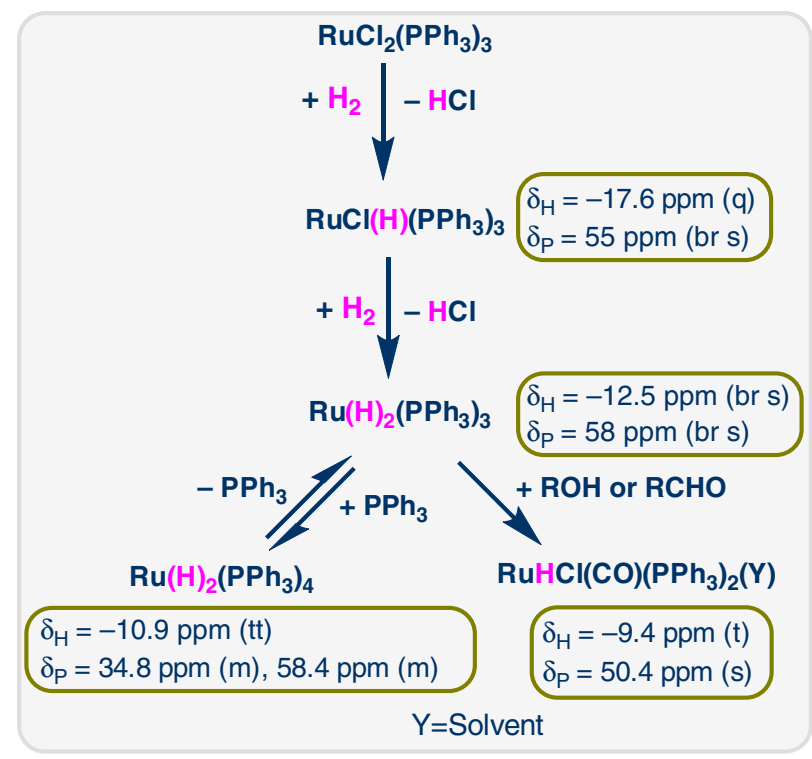

Fig. 7 Generation of different species from $\mathrm{RuCl}_{2}\left(\mathrm{PPh}_{3}\right)_{3}$ in presence of hydrogen. $\mathrm{RuCl}_{2}\left(\mathrm{PPh}_{3}\right)_{2}=$ precatalyst; $\mathrm{Ru}(\mathrm{H}) \mathrm{Cl}\left(\mathrm{PPh}_{3}\right)_{3}$ and $\mathrm{Ru}(\mathrm{H})_{2}\left(\mathrm{PPh}_{3}\right)_{3}$ $=$ active catalytic species

Also, a number of previously reported ruthenium systems for reductive amination as well as alcohol amination are based on carbonyl-containing (pre-)catalysts ${ }^{26,27,35-37}$. Therefore, the question arises whether our active catalyst contains a carbonyl ligand or if it conforms to a previously proposed $\left[\mathrm{RuHX}\left(\mathrm{PPh}_{3}\right)_{3}\right]$ structure $\left(\mathrm{X}=\mathrm{H}^{-} \text {or } \mathrm{Cl}^{-}\right)^{68,69}$. To answer this question, we have compared the catalytic performance of $\left[\mathrm{RuHCl}\left(\mathrm{PPh}_{3}\right)_{3}\right]$ and $\left[\mathrm{RuHCl}(\mathrm{CO})\left(\mathrm{PPh}_{3}\right)_{3}\right]$ for benzaldehyde amination under standard reaction conditions. Interestingly, $\left[\mathrm{RuHCl}\left(\mathrm{PPh}_{3}\right)_{3}\right]$ performs similarly to $\mathrm{RuCl}_{2}\left(\mathrm{PPh}_{3}\right)_{3}$ (88\% benzylamine, $4 \%$ benzyl alcohol, 7\% dibenzylamine; Supplementary Figure 2). This confirms that $\left[\mathrm{RuHCl}\left(\mathrm{PPh}_{3}\right)_{3}\right]$ is part of the transformation cascade (as observed in our model system) which also includes the active catalyst. However, $\left[\mathrm{RuHCl}(\mathrm{CO})\left(\mathrm{PPh}_{3}\right)_{3}\right]$ showed poor selectivity under our reaction conditions (3\% benzylamine, 5\% benzyl alcohol, 90\% N-benzylidenebenzylamine; Supplementary Figure 3). In addition, a reported $\mathrm{Ru}_{3}(\mathrm{CO})_{12}$ /CataCxiumPCy catalytic system, which was used in the amination of alcohols with ammonia $^{36}$, was also tested for the reductive amination of cyclohexanone (Supplementary Figure 3). Similarly, this catalyst also showed poor selectivity, yielding only $10 \%$ of cyclohexylamine. Therefore, carbonyl-containing complexes are likely not the active species under our reaction conditions. Rather, due to their decreased selectivity, they constitute a possible deactivation pathway for $\mathrm{RuCl}_{2}\left(\mathrm{PPh}_{3}\right)_{3}$ catalyzed reductive amination. This difference between our observations and previously reported carbonyl-containing ruthenium amination catalysts is attributed to the ligand: carbonyl-containing $\mathrm{Ru}(\mathrm{II})$ catalysts typically require bidentate ${ }^{26}$ or tridentate ${ }^{35}$ ligands. Control experiments have shown significantly decreased yield in the absence of those additional ligands ${ }^{26}$. In contrast, the carbonyl-free catalyst type $\left[\mathrm{RuHX}\left(\mathrm{PPh}_{3}\right)_{3}\right]$ appears to be sufficiently active and selective with only $\mathrm{PPh}_{3}$-derived ligands.

After clarifying the pathway for catalyst activation we were interested to investigate the reaction cascade starting from the aldehyde/ketone and ammonia using the benzaldehyde benchmark system. The starting materials can undergo a condensation to form primary imine $\mathbf{A}$. Intermediate $\mathbf{A}$, however, was never detected in the reaction mixture, presumably due to its high reactivity. Instead (as can be seen in Fig. 1a), secondary imine 4 was determined to be the major intermediate. 4 is formed via condensation of the product 2 with either the starting aldehyde/ ketone (releasing water) or via condensation of $\mathbf{2}$ and $\mathbf{A}$ (releasing 


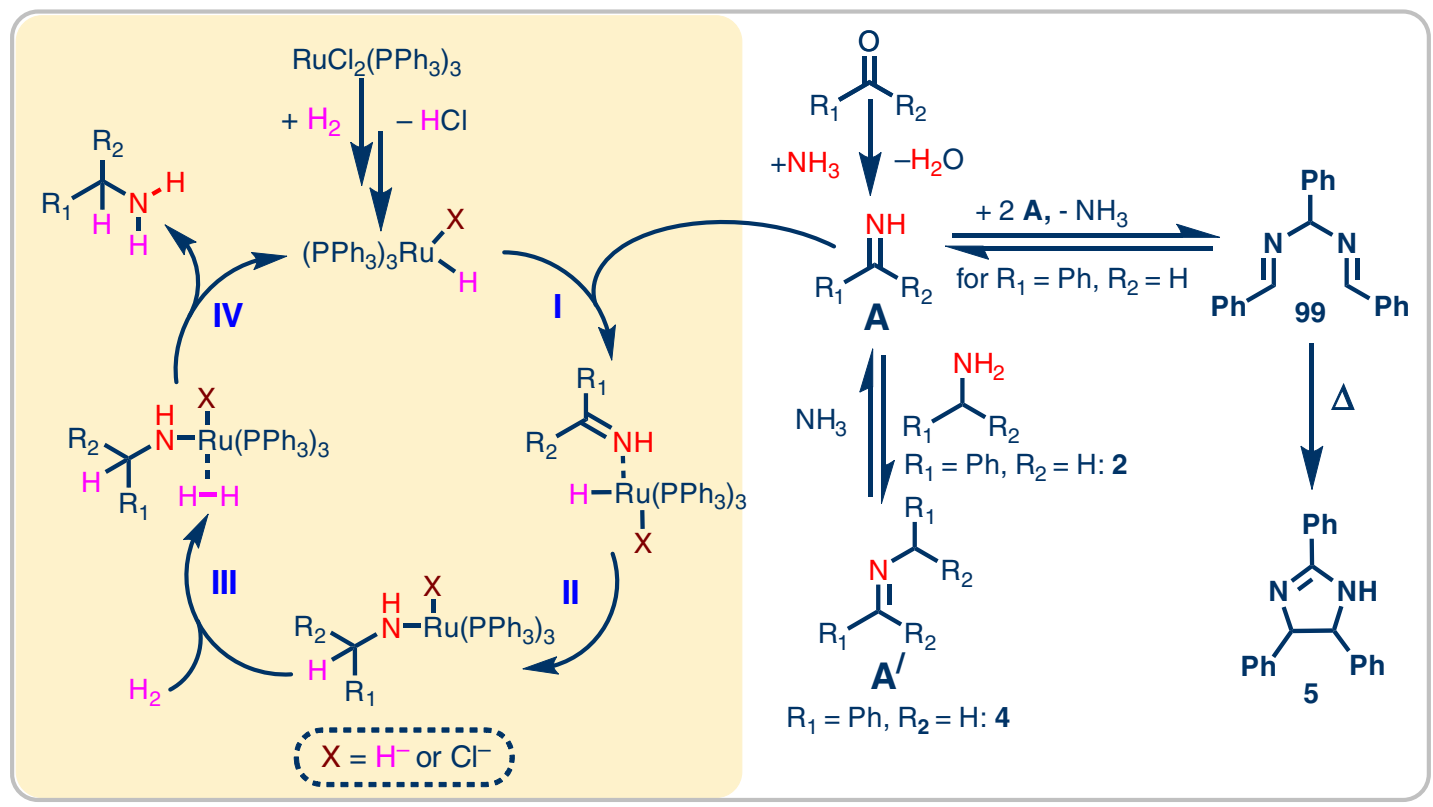

Fig. 8 Proposed reaction mechanism for the $\mathrm{RuCl}_{2}\left(\mathrm{PPh}_{3}\right)_{3}$-catalyzed reductive amination. $\mathbf{A}$ Unstable primary imine; $\mathbf{A} /$ stable secondary imine. $\mathbf{5}=2,4,5-$ triphenyl-2-imidazoline

$\mathrm{NH}_{3}$ ). We next reacted isolated 4 under our standard reaction conditions (40 bar $\mathrm{H}_{2}, 5-7$ bar $\mathrm{NH}_{3}, 24 \mathrm{~h}, \mathrm{RuCl}_{2}\left(\mathrm{PPh}_{3}\right)_{3}$ ) and found almost quantitative conversion to 2 (Supplementary Figure 4). In contrast, when 4 was reacted in the absence of ammonia, 98\% dibenzylamine was obtained after $24 \mathrm{~h}$ (Supplementary Figure 4). These results show that $\mathbf{4}$, when exposed to $\mathrm{NH}_{3}$, is in an equilibrium with $\mathbf{A}+\mathbf{2}^{70}$. While the catalyst is able to hydrogenate both $\mathrm{A}$ and $\mathbf{4}, \mathrm{A}$ is hydrogenated preferentially and is replenished by the equilibrium with 4 . If ammonia is absent or only present in low concentrations (see Fig. 1e), the formation of $\mathbf{A}+\mathbf{2}$ from $\mathbf{4}$ is suppressed, leading to hydrogenation of 4 (yielding dibenzlamine). Furthermore, due to rapid hydrogenation under optimized conditions, the stationary concentration of $\mathbf{A}$ is low, precluding side reactions of this reactive intermediate. When the hydrogenation does not proceed quickly, however, accumulation and side reactions involving $\mathbf{A}$ can likely occur. Correspondingly, when a mixture of $\mathbf{4}$ and benzaldehyde was reacted under standard conditions but without $\mathrm{H}_{2}, 20 \%$ of the cyclic side-product 5 was obtained (the rest being unreacted starting material, see Supplementary Figure 5). Williams et al. ${ }^{71}$ and Corey et al. ${ }^{72}$ have reported that $\mathbf{A}$ can trimerize to form $\mathbf{9 9}$, which can subsequently undergo thermal cyclization to form $\mathbf{5}$ (Fig. 8). This reaction of accumulated A likely explains the formation of large amounts of $\mathbf{5}$ in less active catalyst systems (see Table 1, entries 1-10; Fig. 1).

Based on these observations we propose the following mechanism (Fig. 8): Reaction of a carbonyl compound with $\mathrm{NH}_{3}$ yields primary imine $\mathbf{A}$, which can be in an equilibrium with secondary imine $\mathbf{A}^{\prime}$ via condensation with the product amine. The precatalyst $\mathrm{RuCl}_{2}\left(\mathrm{PPh}_{3}\right)_{3}$ is activated by $\mathrm{H}_{2}$ to form the the active catalyst species [RuHX $\left(\mathrm{PPh}_{3}\right)_{3}$ ] $\left(\mathrm{X}\right.$ being either $\mathrm{H}^{-}$or $\left.\mathrm{Cl}^{-}\right)$. This active catalytic species selectively reacts with the primary imine to initially form a substrate complex (I). Substrate coordination is followed by hydride insertion (II), generating a $\mathrm{Ru}$ amide complex. Coordination of $\mathrm{H}_{2}$ (III) followed by hydrogenolysis releases the primary amine as the final product with regeneration of the catalytic species (IV).

In conclusion, we demonstrated that using a simple $\mathrm{RuCl}_{2}\left(\mathrm{PPh}_{3}\right)_{3}$ catalyst, the challenging reductive amination of carbonyl compounds using ammonia and molecular hydrogen for the selective synthesis of a variety of primary amines is possible. Applying this Ru-based reductive amination, starting from inexpensive aldehydes and ketones, functionalized and structurally diverse linear and branched primary amines have been synthesized under industrially viable and scalable conditions. In general, achieving a high degree of chemoselectivity in amination/hydrogenation reactions is a challenging task. In this regard our simple Ru-based methodology represents a unique example in homogeneous catalysis for the reductive amination of functionalized and challenging molecules. We have also shown the possibility of scaling this amination protocol up to $10 \mathrm{~g}$ without any loss in either activity or selectivity. The application of this approach is also extended to the synthesis and amination of various drug molecules and steroid derivatives. In situ NMR investigations provided clear hints on the formation of Ru-hydride species, which have been elucidated to be the active catalytic species in this $\mathrm{RuCl}_{2}\left(\mathrm{PPh}_{3}\right)_{3^{-}}$ catalyzed reductive amination. With the help of these investigations, an appropriate reaction mechanism has been proposed.

\section{Methods}

General considerations. All carbonyl compounds (aldehydes and ketones), Ruprecursors and complexes and ligands, were obtained commercially. All catalytic experiments were carried out in 300,100 , and $500 \mathrm{~mL}$ autoclaves (PARR Instrument Company). In order to avoid unspecific reactions, all catalytic reactions were carried out either in glass vials, which were placed inside the autoclave, or glass/ Teflon vessel fitted autoclaves. GC and GC-MS were recorded on a Agilent 6890N instrument. GC conversion and yields were determined by GC-FID, HP6890 with FID detector, column HP530 $\mathrm{m} \times 250 \mathrm{~mm} \times 0.25 \mu \mathrm{m} .{ }^{1} \mathrm{H},{ }^{13} \mathrm{C}$ NMR data were recorded on a Bruker AV 300 and Bruker AV 400 spectrometers using DMSO- $\mathrm{d}_{6}$, $\mathrm{CD}_{3} \mathrm{OD}$ or $\mathrm{C}_{6} \mathrm{D}_{6}$ as solvents. $\mathrm{Ru}$ (tris(4-methoxyphenyl)phosphine) ${ }_{3} \mathrm{Cl}_{2}$ and $\mathrm{Ru}$ (tris (4-chlorophenyl)phosphine) ${ }_{3} \mathrm{Cl}_{2}$ were prepared according to the reported procedure $^{73}$.

Reductive amination of carbonyl compounds with ammonia. The $8 \mathrm{~mL}$ dried glass vial was charged with a magnetic stirring bar and $0.5 \mathrm{mmol}$ of corresponding carbonyl compound (aldehyde or ketone). Then $1.5 \mathrm{~mL} \mathrm{t}$-amyl alcohol as solvent and $2-3 \mathrm{~mol} \% \mathrm{RuCl}_{2}\left(\mathrm{PPh}_{3}\right)_{3}$ catalysts $(2 \mathrm{~mol} \%$ in case of aldehydes and $3 \mathrm{~mol} \%$ in case of ketones) were added. The glass vial was fitted with a septum, cap and needle, and placed into a $300 \mathrm{~mL}$ autoclave (eight vials with different substrates at a time). The autoclave was flushed with hydrogen twice at 40 bar pressure and then it was pressurized with 5-7 bar ammonia gas and 40 bar hydrogen. The autoclave was 
placed into an aluminum block preheated at $140^{\circ} \mathrm{C}$ (placed inside $30 \mathrm{~min}$ before counting the reaction time in order to attain the reaction temperature) and the reactions were stirred for the required time. During the reaction the inside temperature of the autoclave was measured to be $130^{\circ} \mathrm{C}$ and this temperature was used as the reaction temperature. After completion of the reactions, the autoclave was cooled to room temperature. The remaining ammonia and hydrogen were discharged and the vials containing reaction products were removed from the autoclave. The reaction products were analyzed by GC-MS and the corresponding primary amines were purified by column chromatography (silica; n-hexane-ethyl acetate mixture). The resulting amines were converted to their respective hydrochloride salt and characterized by NMR. For conversion into the hydrochloride salt, $1-2 \mathrm{~mL}$ methanolic $\mathrm{HCl}$ or dioxane $\mathrm{HCl}(1.5 \mathrm{M} \mathrm{HCl}$ in methanol or $4 \mathrm{~N} \mathrm{HCl}$ in dioxane) was added to the ether solution of the respective amine and stirred at room temperature for $4-5 \mathrm{~h}$. Then, the solvent was removed and the resulting hydrochloride salt of the amine was dried under high vacuum. For determining the yields by GC for selected amines, after completion of the reaction $\mathrm{n}$-hexadecane $(100 \mu \mathrm{L})$ as standard was added to the reaction vials and the reaction products were diluted with ethyl acetate followed by filtration using a plug of silica and then analyzed by GC.

General procedure for the gram scale reactions. The Teflon or glass fitted 300 $(5-10 \mathrm{~g})$ or $500 \mathrm{~mL}(20 \mathrm{~g})$ (in case $5-20 \mathrm{~g}$ ) or $100 \mathrm{~mL}$ (in case of 2-2.5 g) autoclave was charged with a magnetic stirring bar and the corresponding carbonyl compound $(2-20 \mathrm{~g})$. Then $25-150 \mathrm{~mL}$ t-amyl alcohol was added. Subsequently, $\mathrm{RuCl}_{2}\left(\mathrm{PPh}_{3}\right)_{3}$ (amount of catalysts equivalent to $2-3 \mathrm{~mol} \%$ ) was added. The autoclave was flushed with hydrogen twice at 40 bar pressure and then it was pressurized with 5-7 bar ammonia gas and 40 bar hydrogen. The autoclave was placed into an aluminum block preheated to $140{ }^{\circ} \mathrm{C}$ (placed $30 \mathrm{~min}$ before counting the reaction time in order to attain reaction temperature) and the reaction was stirred for the required time. During the reaction the inside temperature of the autoclave was measured to be $130{ }^{\circ} \mathrm{C}$ and this temperature was used as the reaction temperature. After completion of the reaction, the autoclave was cooled to room temperature. The remaining ammonia and hydrogen were discharged and the reaction products were removed from the autoclave. The reaction products were analyzed by GC-MS and the corresponding primary amines were purified by column chromatography (silica; $n$-hexane-ethyl acetate mixture). The resulting amines were converted to their respective hydrochloride salt and characterized by NMR.

Procedure for the in situ NMR studies. The in situ observation of the $\mathrm{Ru}-$ hydrides was performed under hydrogen saturation conditions in a $5 \mathrm{~mm}$ glass NMR tube, equipped with a PTFE gas inlet hose and a circulation unit which produces a continuous gas flow through the solution ${ }^{74,75}$. The brown solution of the precursor complex $\mathrm{RuCl}_{2}\left(\mathrm{PPh}_{3}\right)_{3}(50 \mathrm{mg})$ in $0.5 \mathrm{~mL}$ methanol/ $0.5 \mathrm{~mL}$ benzened6 was transferred to the NMR tube under Ar. After assembling the device under inert gas and characterizing the solution by its ${ }^{1} \mathrm{H}$ and ${ }^{31} \mathrm{P}$ NMR spectra, the system was filled with neat hydrogen (absolute pressure 1.5 bar). A gas flow of 1 $\mathrm{mL} \mathrm{min}^{-1}$ was used to saturate the solution. ${ }^{1} \mathrm{H}$ and ${ }^{31} \mathrm{P}$ NMR spectra were taken at regular intervals to monitor the reaction progress. Changes were immediately observable as shown in Fig. 2. After three hours, the temperature was raised and kept at about $60^{\circ} \mathrm{C}$ for another three hours to complete the reaction. No further changes were detected thereafter. The color of the solution was changed to brickred at the end of the experiment. Note that maintaining a continuous gas flow till the very end was not possible, because black particles of precipitating metallic $\mathrm{Ru}$ were clogging the tubing.

\section{Data availability}

All data are available from the authors upon reasonable request.

Received: 4 May 2018 Accepted: 4 September 2018

Published online: 08 October 2018

\section{References}

1. Lawrence, S. A. Amines: Synthesis, Properties and Applications. (Cambridge University Press, Cambridge, UK, 2004).

2. Ricci, A. Amino Group Chemistry: From Synthesis to the Life Sciences. (Wiley$\mathrm{VCH}$, Weinheim, 2008).

3. Smith, D. T., Delost, M. D., Qureshi, H. \& Njarðarson, J. T. Top 200 Pharmaceutical Products by Retail Sales in 2016. https://njardarson.lab. arizona.edu/sites/njardarson.lab.arizona.edu/files/ 2016Top200PharmaceuticalRetailSalesPosterLowResV3_0.pdf (2017).

4. Roughley, S. D. \& Jordan, A. M. The medicinal chemist's toolbox: an analysis of reactions used in the pursuit of drug candidates. J. Med. Chem. 54, 3451-3479 (2011).

5. Froidevaux, V., Negrell, C., Caillol, S., Pascault, J.-P. \& Boutevin, B. Biobased amines: from synthesis to polymers; present and future. Chem. Rev. 116, 14181-14224 (2016).
6. Mao, R., Frey, A., Balon, J., Hu, X. \& Decarboxylative, C. (sp $\left.{ }^{3}\right)-\mathrm{N}$ crosscoupling via synergetic photoredox and copper catalysis. Nat. Catal. 1, 120-126 (2018)

7. Gomez, S. A., Peters, J. A. \& Maschmeyer, T. The reductive amination of aldehydes and ketones and the hydrogenation of nitriles: mechanistic aspects and selectivity control. Adv. Synth. Catal. 344, 1037-1057 (2002).

8. Alinezhad, H., Yavari, H. \& Salehian, F. Recent advances in reductive amination catalysis and its applications. Curr. Org. Chem. 19, 1021-1049 (2015).

9. Nugenta, T. C. \& El-Shazlya, M. Chiral amine synthesis-recent developments and trends for enamide reduction, reductive amination, and imine reduction. Adv. Synth. Catal. 352, 753-819 (2010).

10. Wakchaure, V. N., Zhou, J., Hoffmann, S. \& List, B. Catalytic asymmetric reductive amination of a-branched ketones. Angew. Chem. Int. Ed. 49, 4612-4614 (2010).

11. Chusov, D. \& B. List, B. Reductive amination without an external hydrogen source. Angew. Chem. Int. Ed. 53, 5199-5201 (2014).

12. Natte, K., H. Neumann, H., Jagadeesh, R. V. \& Beller, M. Convenient ironcatalyzed reductive aminations without hydrogen for selective synthesis of $\mathrm{N}$ methylamines. Nat. Commun. 8, 1344 (2017).

13. Jagadeesh, R. V. et al. Hydrogenation using iron oxide-based nanocatalysts for the synthesis of amines. Nat. Protoc. 10, 548-557 (2015).

14. Reductive amination. https://www.reagentguides.com/reagent-guides/ reductive-amination (2015).

15. Gusak, K. N., Ignatovich, Z. V. \& Koroleva, E. V. New potential of the reductive alkylation of amines. Russ. Chem. Rev. 84, 288-309 (2015).

16. Senthamarai, T. et al. Expedient synthesis of N-methyl- and $\mathrm{N}$-alkylamines by reductive amination using reusable cobalt oxide nanoparticles. ChemCatChem 10, $1235-1240$ (2018)

17. Jagadeesh, R. V. et al. MOF-derived cobalt nanoparticles catalyze a general synthesis of amines. Science 358, 326-332 (2017).

18. Komanoya, T., Kinemura, T., Kita, Y., Kamata, Y. K. \& Hara, M. Electronic effect of ruthenium nanoparticles on efficient reductive amination of carbonyl compounds. J. Am. Chem. Soc. 139, 11493-11499 (2017).

19. Nakamura, Y., Kon, K., Touchy, A. S., Shimizu, K.-i. \& Ueda, W. Selective synthesis of primary amines by reductive amination of ketones with ammonia over supported Pt catalysts. ChemCatChem 7, 921-924 (2015).

20. Liang, G. et al. Production of primary amines by reductive amination of biomassderived aldehydes/ketones. Angew. Chem. Int. Ed. 56, 3050-3054 (2017).

21. Wang, Z. Mignonac reaction. In Comprehensive organic name reactions and reagents. (John Wiley \& Sons, New Jersey, 2010).

22. Chatterjee, M., Takayuki Ishizakaa, T. \& Kawanami, H. Reductive amination of furfural to furfurylamine using aqueous ammonia solution and molecular hydrogen: an environmentally friendly approach. Green. Chem. 18, 487-496 (2016).

23. Reductive amination review. https://erowid.org/archive/rhodium/chemistry/ reductive.amination.html (2004).

24. Gross, T., Seayad, A. M., Ahmad, M. \& Beller, M. Synthesis of primary amines: first homogeneously catalyzed reductive amination with ammonia. Org. Lett. 4, 2055-2058 (2002).

25. Riermeier, T. et al. Method for producing amines by homogeneously catalyzed reductive amination of carbonyl compounds. US 6, 884-887 B1 (2005).

26. Gallardo-Donaire, J., Ernst, M., Trapp, O. \& Schaub, T. Direct synthesis of primary amines via ruthenium-catalysed amination of ketones with ammonia and hydrogen. Adv. Synth. Catal. 358, 358-363 (2016).

27. Gallardo-Donaire, J. et al. Direct asymmetric ruthenium-catalyzed reductive amination of alkyl-aryl ketones with ammonia and hydrogen. J. Am. Chm. Soc. 140, 355-361 (2018).

28. Ogo, S., Uehara, K., Abura, T. \& Fukuzumi, S. pH-Dependent chemoselective synthesis of $\alpha$-amino acids. Reductive amination of $\alpha$-keto acids with ammonia catalyzed by acid-stable iridium hydride complexes in water. J. Am. Chm. Soc. 126, 3020-3021 (2004).

29. Kadyrov, R. \& Riermeier, T. H. Highly enantioselective hydrogen-transfer reductive amination: catalytic asymmetric synthesis of primary amines. Angew. Chem. Int. Ed. 42, 5472-5474 (2003).

30. Tan, X. et al. Asymmetric synthesis of chiral primary amines by rutheniumcatalyzed direct reductive amination of alkyl aryl ketones with ammonium salts and molecular $\mathrm{H}_{2}$. J. Am. Chem. Soc. 140, 2024-2027 (2018).

31. Yan, T., Feringa, B. L. \& Barta, K. Iron catalysed direct alkylation of amines with alcohols. Nat. Commun. 5, 5602 (2014).

32. Meindl, W. R., Angerer, E. V., Schoenenberger, H. \& Ruckdeschel, G. Benzylamines: synthesis and evaluation of antimycobacterial properties. $J$. Med. Chem. 27, 1111-1118 (1984)

33. Yan, T., Feringa, B. L. \& Barta, K. Direct $\mathrm{N}$-alkylation of unprotected amino acids with alcohols. Sci. Adv. 3, eaao6494 (2017).

34. Goldacre, R. J. Mode of action of benzylamine sulphonamide ('Marfanil'). Nature 154, 796-797 (1944) 
35. Gunanathan, C. \& Milstein, D. Selective synthesis of primary amines directly from alcohols and ammonia. Angew. Chem. Int. Ed. 47, 8661-8664 (2008).

36. Imm, S., Bähn, S., Neubert, L., Neumann, H. \& Beller, M. An efficient and general synthesis of primary amines by ruthenium-catalyzed amination of secondary alcohols with ammonia. Angew. Chem Int. Ed. 49, 8126-8129 (2010).

37. Pingen, D., Müller, C. \& Vogt, D. Direct amination of secondary alcohols using ammonia. Angew. Chem. Int. Ed. 49, 8130-8133 (2010).

38. Bähn, S. et al. The catalytic amination of alcohols. ChemCatChem 3, 1853-1864 (2011).

39. Leuckart, R. Ueber eine neue bildungsweise von tribenzylamin. Ber 18, 2341-2344 (1885).

40. Moore, M. L. Organic Reactions (Wiley, Hoboken, NJ, 2011).

41. Crossley, F. S. \& Moore, M. L. Studies on Leuckart reaction. J. Org. Chem. 9, 529-536 (1944).

42. Feuer, H. \& Braunstein, D. M. Reduction of oximes, oxime ethers, and oxime esters with diborane. Nov. Synth. Amines J. Org. Chem. 34, 1817-1821 (1969).

43. Huang, X. et al. Asymmetric synthesis of primary amines via the spiroboratecatalyzed borane reduction of oxime ethers. Org. Lett. 9, 1793-1795 (2007).

44. Mirjafary, Z., Abdoli, M., Saeidian, H., Boroon, S. \& Kakanejadifard, A. Oxime ethers as versatile precursors in organic synthesis: a review. RSC $A d v . \mathbf{5}$, 79361-79384 (2015).

45. Ammonia. https://pubchem.ncbi.nlm.nih.gov/compound/ammonia (2016)

46. Appl, M. in Ullmann's Encyclopedia of Industrial Chemistry, 7th edn. (ed. Wiley-VCH) (Wiley, New York, 2011).

47. van Gysel, A. B. \& Musin, W. in Ullmann's Encyclopedia of Industrial Chemistry, 7th edn. (ed. Wiley-VCH) (Wiley, New York, 2011).

48. Schirmann, P. \& Bourdauducq, J.-P. in Ullmann's Encyclopedia of Industrial Chemistry, 7th edn. (ed. Wiley-VCH) (Wiley, New York, 2011).

49. Klinkenberg, J. L. \& Hartwig, J. F. Catalytic organometallic reactions of ammonia. Angew. Chem. Int. Ed. 50, 86-95 (2011).

50. Schranck, J. \& Tlili, A. Transition-metal-catalyzed monoarylation of ammonia. ACS Catal. 8, 405-418 (2018).

51. Cobb, J. E. et al. In Encyclopedia of Reagents for Organic Synthesis (eds. Paquette, L. A. et al.) (John Wiley \& Sons, New York, 2004).

52. Burke, S. D. \& Danheiser, R. L. Triphenylphosphine, Handbook of Reagents for Organic synthesis, Oxidizing and Reducing Agents (Wiley, Hoboken, NJ, 1999).

53. Pignolet, L. M. Homogeneous Catalysis with Metal Phosphine Complexes (Springer US, 2013).

54. Wilkinson's catalyst, Comprehensive Organic Name Reactions and Reagents (2010).

55. Müller, C. \& Vogt, D. Phosphinines as ligands in homogeneous catalysis: Recent developments, concepts and perspectives. Dalton. Trans. 5505-5523 (2007).

56. Plummer, J. S., Shun-Ichi, M. \& Changjia, Z. Dichlorotris (triphenylphosphine)ruthenium(II), e-EROS Encyclopedia of Reagents for Organic Synthesis (John Wiley, 2010).

57. Crabtree, R. H. Homogeneous transition metal catalysis of acceptorless dehydrogenative alcohol oxidation: applications in hydrogen storage and to heterocycle synthesis. Chem. Rev. 117, 9228-9246 (2017).

58. Guillena, G., Ramon, D. J. \& Yus, M. Hydrogen autotransfer in the Nalkylation of amines and related compounds using alcohols and amines as electrophiles. Chem. Rev. 110, 1611-1641 (2010).

59. Sameca, J. S. M., Bäckvall, J.-E., Andersson, P. G. \& Brandt, P. Mechanistic aspects of transition metal-catalyzed hydrogen transfer reactions. Chem. Soc. Rev. 35, 237-248 (2006).

60. Pingen, D., Lutz, M. \& Vogt, D. Mechanistic study on the ruthenium-catalyzed direct amination of alcohols. Organometallics 33, 1623-1629 (2014).

61. Evans, D., Osborn, J. A., Jardine, F. H. \& Wilkinson, G. Homogeneous hydrogenation and hydroformylation using ruthenium complexes. Nature 208, 1203-1204 (1965).

62. Wang, G.-Z. \& Bäckvall, J. E. Ruthenium-catalysed transfer hydrogenation of imines by propan-2-ol. Chem. Commun. 980-982 (1992).

63. Kirss, R. U., Eisenschmid, T. C. \& Eisenberg, R. Para hydrogen induced polarization in hydrogenation reactions catalyzed by ruthenium phosphine complexes. J. Am. Chem. Soc. 110, 8564-8566 (1988).

64. Samouei, H., Miloserdov, F. M., Escudero-Adán, E. C. \& Grushin, V. V. Solidstate structure and solution reactivity of $\left[\left(\mathrm{Ph}_{3} \mathrm{P}\right)_{4} \mathrm{Ru}(\mathrm{H})_{2}\right]$ and related $\mathrm{Ru}(\mathrm{II})$ complexes used in catalysis: a reinvestigation. Organometallics 33, 7279-7283 (2014).

65. Mazziotta, A. \& Madsen, R. Ruthenium-catalyzed dehydrogenative decarbonylation of primary alcohols. Eur. J. Org. Chem. 36, 5417-5420 (2017).

66. Van der Sluys, L. S., Kubas, G. J. \& Caulton, K. G. Reactivity of (dihydrogen) dihydridotris(triphenylphosphine)ruthenium. Dimerization to form
$\left(\mathrm{PPh}_{3}\right)_{2}(\mathrm{H}) \mathrm{Ru}(. \mathrm{mu} .-\mathrm{H})_{3} \mathrm{Ru}\left(\mathrm{PPh}_{3}\right)_{3}$ and decarbonylation of ethanol under mild conditions. Organometallics 10, 1033-1038 (1991).

67. MaŁecki, J. G. \& Kruszynski, R. Synthesis, crystal and spectroscopic characterization of $\left[\mathrm{RuHCl}(\mathrm{CO})\left(\mathrm{PPh}_{3}\right)_{2}\right.$ (pyrazine)]. J. Coord. Chem. 60, 2085-2095 (2007).

68. Aranyos, A., Csjernyik, G., Szabo, K. S. \& Bäckvall, J. E. Evidence for a ruthenium dihydride species as the active catalyst in the $\mathrm{RuCl}_{2}\left(\mathrm{PPh}_{3}\right)$ catalyzed hydrogen transfer reaction in the presence of base. Chem. Commun. 351-352 (1999).

69. Masters, C. Homogeneous Transition-Metal Catalysis: A Gentle Art. 51-55 (Chapman \& Hall, 1981).

70. Krupka, J., Dluhoš, L. \& Mrózek, L. Evaluation of benzylamine production via reductive amination of benzaldehyde in a slurry reactor. Chem. Eng. Technol. 40, 870-877 (2017).

71. Williams, O. F. \& Bailar, J. C. The stereochemistry of complex inorganic compounds. XXIV. Cobalt stibenediamine complexes. J. Am. Chem. Soc. 81, 4464-4469 (1959)

72. Corey, E. J. \& Kühnle, F. N. M. A simplified synthesis of ( \pm )-1,2-diphenyl1,2-diaminoethane (1) from benzaldehyde and ammonia. Revision of the structures of the long-known intermediates "hydrobenzamide" and "amarine. Tetrahedron Lett. 38, 8631-8634 (1997).

73. Samouei, H., Vladimir, V. \& Grushin, V. V. New, highly efficient, simple, safe, and scalable synthesis of $\left[\left(\mathrm{Ph}_{3} \mathrm{P}\right)_{3} \mathrm{Ru}(\mathrm{CO})(\mathrm{H})_{2}\right]$. Organometallics 32, 4440-4443 (2013)

74. Baumann, W., Mansel, S., Heller, D. \& Borns, S. Gas bubbles in the NMR tube: an easy way to investigate reactions with gases in the liquid phase. Magn. Reson. Chem. 35, 701-706 (1997).

75. Baumann, W., Börner, A., Selent, D. Gas injection and circulation device for tracking of reactions in the liquid phase involving gaseous reactants under normal and high pressure by means of nuclear magnetic resonance spectroscopy (NMR spectroscopy pressure) under steady state conditions. DE10333143B4, 2008.

\section{Acknowledgements}

We gratefully acknowledge the European Research Council (EU project 670986-NoNaCat) and the State of Mecklenburg-Vorpommern for financial and general support. Financial support by Fonds der Chemischen Industrie (Kekulé-Stipendium n. 102151) for J.S. is also acknowledged. We thank the analytical staff of the Leibniz-Institute for Catalysis, Rostock for their excellent service.

\section{Author contributions}

R.V.J., T.S., K.M., M.B., and N.V.K. planned and developed the project. T.S., K.M., R.V.J. J.S., N.V.K., H.N., and P.C.J.K. designed the experiments. T.S. and K.M. performed catalytic experiments. W.B. and J.S. performed in situ NMR experiments. R.V.J., J.S., N.V.K., T.S., K.M., P.C.J.K., and M.B. wrote the paper. R.V.J. and M.B. supervised the project.

\section{Additional information}

Supplementary Information accompanies this paper at https://doi.org/10.1038/s41467018-06416-6.

\section{Competing interests: The authors declare no competing interests.}

Reprints and permission information is available online at http://npg.nature.com/ reprintsandpermissions/

Publisher's note: Springer Nature remains neutral with regard to jurisdictional claims in published maps and institutional affiliations.

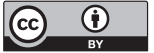

Open Access This article is licensed under a Creative Commons Attribution 4.0 International License, which permits use, sharing, adaptation, distribution and reproduction in any medium or format, as long as you give appropriate credit to the original author(s) and the source, provide a link to the Creative Commons license, and indicate if changes were made. The images or other third party material in this article are included in the article's Creative Commons license, unless indicated otherwise in a credit line to the material. If material is not included in the article's Creative Commons license and your intended use is not permitted by statutory regulation or exceeds the permitted use, you will need to obtain permission directly from the copyright holder. To view a copy of this license, visit http://creativecommons.org/ licenses/by/4.0/.

(C) The Author(s) 2018 